\title{
Prostatic Lymphoma Masquerading as Urinary Retention and Hematuria With Review of Literature
}

\author{
Tsering Gyalpo Lama Tamang, e, Prabhsimranjot Singh ${ }^{\mathrm{b}}$, e, f, Jonathan Garellek ${ }^{\mathrm{a}}$, \\ Sonali Malhotra ${ }^{\mathrm{c}}$, Abhinav Binod Chandra ${ }^{\mathrm{d}}$, William Solomon ${ }^{\mathrm{b}}$
}

\begin{abstract}
Lymphomas of prostate are very rare tumors. They are not commonly considered in the clinical and histological differential diagnosis of prostatic enlargement. We report a case of a 49-year-old man who presented to emergency department with several weeks of difficulty in urination, for which he was being treated for benign prostate hyperplasia with no improvement. Computerized tomography scan showed lobulated mass originating from the superior aspect of the prostate with right inguinal lymph node involvement and no distant organ metastatic disease. Prostatic biopsy revealed diffuse large B-cell lymphoma. The patient achieved complete remission after six cycles of rituximab, cyclophosphamide, doxorubicin, vincristine, and prednisone chemotherapy regimen. Lymphomas of the prostate should be considered in differential diagnosis of the patient presenting with obstructive lower urinary tract symptoms especially in patients with normal prostatic-specific antigen level and previous history of lymphoma in other sites.
\end{abstract}

Keywords: Prostate; Lymphoma; Non-Hodgkin diffuse-large B-cell lymphoma; Prostate hyperplasia

\section{Introduction}

Primary malignant lymphomas of the prostate account for $0.09 \%$ of all prostate neoplasms and $0.1 \%$ of all non-Hodg-

Manuscript submitted June 23, 2017, accepted July 4, 2017

aDepartment of Internal Medicine, Maimonides Medical Center, Brooklyn, NY, USA

${ }^{\mathrm{b}}$ Department of Hematology/Oncology, Maimonides Medical, Center, Brooklyn, NY, USA

'Department of Pediatric Endocrinology, Maimonides Medical Center, Brooklyn, NY, USA

dDepartment of Hematology/Oncology, Yuma Regional Medical, Center, Yuma, AZ, USA

eBoth first authors and contributed equally.

fCorresponding Author: Prabhsimranjot Singh, Department of Hematology/ Oncology, Maimonides Medical Center, 950 49th street, Brooklyn, NY 11219, USA. Email: drprabhsimran@gmail.com

doi: https://doi.org/10.14740/wjon1055w kin's lymphomas (NHLs) [1-5]. Lymphoma of the prostate can be primary or secondary $[3,6]$. Because of their rarity, they are not commonly considered in the clinical and histological differential diagnosis of prostatic enlargement. Consideration of this differential diagnosis is important, because of their aggressive behavior and poor short-term outcome, and at the same time it can achieve remission with chemotherapy. We report a case of a 49-year-old man diagnosed with NHL of prostate, who was initially treated for benign prostate hyperplasia (BPH) with no improvement in symptoms of obstructive uropathy. Our case report will add to understanding of etiology, pathogenesis, natural history, and treatment of particularly this rare tumor and to the training of potential future investigators.

\section{Case Report}

A 49-year-old man, current smoker, with past surgical history of cholecystectomy, presented with several weeks history of difficulty in urination, as well as dysuria, pelvic pain and occasional hematuria, with subjective fever. He had been treated with tamsulosin and finasteride as an outpatient with minimal relief. Due to persistent pelvic pain and obstructive uropathy, he was admitted to the hospital. On initial evaluation, patient was noticed to have mild suprapubic tenderness and no costovertebral angle tenderness or urethral discharge. Routine laboratory tests were within normal limits except hemoglobin 11.6, prostatespecific antigen (PSA) $0.4 \mathrm{ng} / \mathrm{mL}$ and lactate dehydrogenase (LDH) 347. Computerized tomography (CT) scan showed a 7 $\times 4 \mathrm{~cm}$ lobulated mass below the base of the bladder, possibly arising from the superior aspect of the prostate and invading the seminal vesicles. There was right pelvic/inguinal adenopathy with largest node measuring $2 \mathrm{~cm}$ posterior to the external iliac vessels and no evidence of distant metastatic disease (Fig. 1). This was further investigated by a prostate biopsy which revealed prostatic tissue with diffuse involvement of sheets of atypical cells with large irregular nuclei, prominent nucleoli numerous mitotic figures with immunohistochemical stains showing the tumor cells positive for $\mathrm{CD} 45^{+}, \mathrm{CD} 20^{+}, \mathrm{BCL}^{+}$, $\mathrm{MUM1}^{+}$, while negative for CD10, BCL6, cyclin-D1, PSA, CK903, and P504S, consistent with diagnosis of a diffuse large B-cell lymphoma (DLBCL), activated B-cell type (Figs. 2 and 3 ). Bone marrow aspirate and biopsy were normal. Our patient was diagnosed with stage IIE bulky NHL of the prostate with low-intermediate risk group as per NCCN-IPI score. He had a 


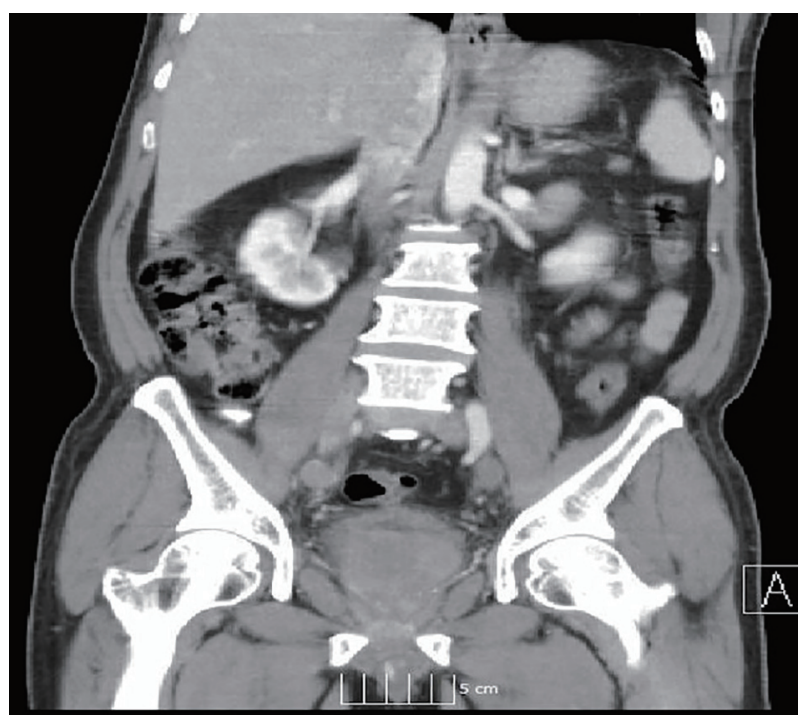

Figure 1. A $7 \times 4 \mathrm{~cm}$ lobulated mass below the base of the bladder, arising from the superior aspect of the prostate and invading the seminal vesicles.

normal echocardiogram and negative hepatitis panel. The patient was subsequently started on chemotherapy with R-CHOP (rituximab, cyclophosphamide, doxorubicin, vincristine and prednisone) regimen. Patient symptoms improved with chemotherapy. After completing six cycles of chemotherapy, patient had a positron emission tomography (PET) scan reporting no hypermetabolic disease and remains in remission and will be followed up closely.

\section{Discussion}

Prostate cancer is the most frequently diagnosed cancer in men accounting for $28 \%$ of new cases and $10 \%$ of cancer-related deaths in the US $[7,8]$.

Adenocarcinoma is the most common prostatic malig-

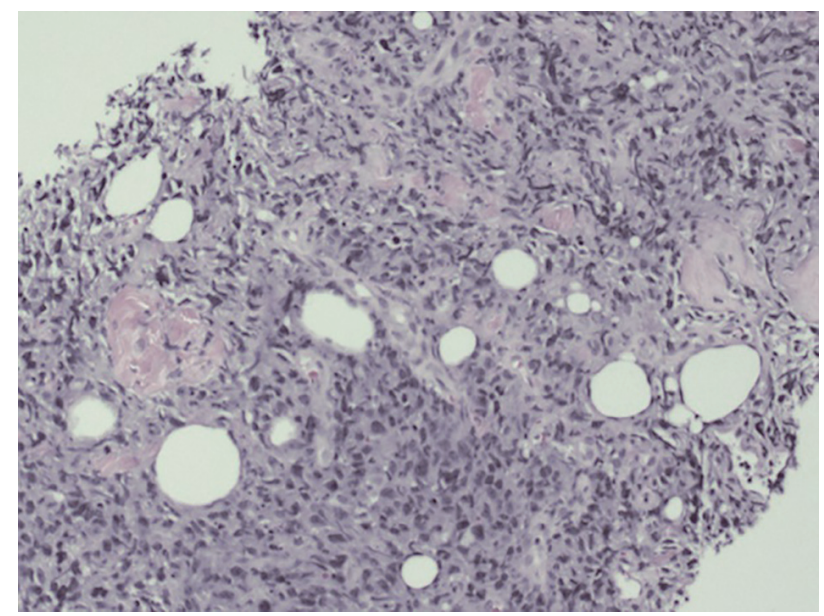

Figure 2. Prostate biopsy: low power view of the prostate core showing a diffuse proliferation of atypical pleomorphic cells.

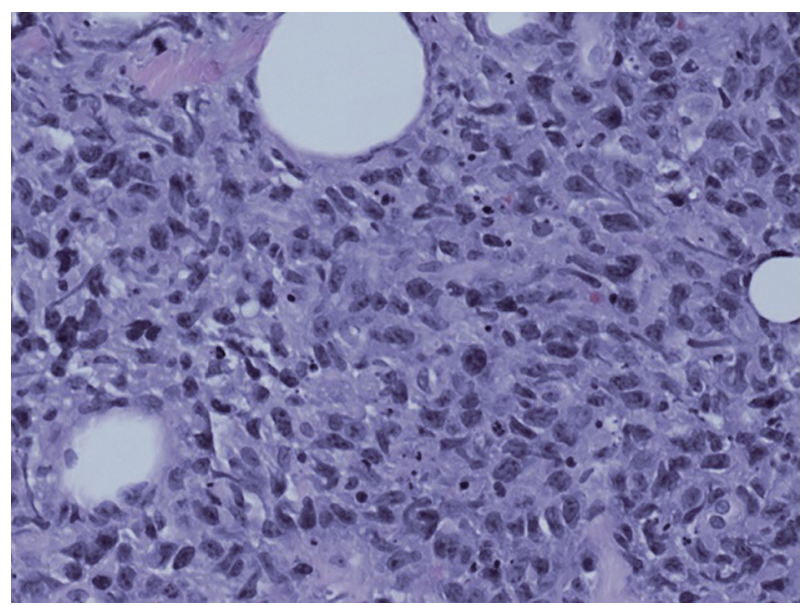

Figure 3. Prostate biopsy: high power $(\times 40)$ view showing cellular pleomorphism and nuclear karyorrhexis.

nancy, representing over $95 \%$ of all prostate cancers [9]. The primary lymphoma of prostate is a rare condition. It is difficult to distinguish clinically from benign prostatic hyperplasia and adenocarcinoma of prostate which also presents with signs and symptoms of lower urinary tract obstruction. So, it is generally not included in differential diagnosis. These patients tend to be elderly with a mean age of 60 years $[3,6,10]$. Most cases of NHLs affecting the prostate are DLBCL, but primary prostatic small lymphocytic lymphoma, follicular lymphomas, Burkitt lymphomas, mucosa-associated lymphoid tissue (MALT) lymphomas, and mantle cell lymphomas have also been reported $[2,3,6,10-14]$. Our patient had DLBCL.

The first diagnostic criterion for primary prostatic lymphoma was established by Bostwick et al, which includes symptoms attributable to prostatic enlargement, the prostate as the predominant site of involvement, and the absence of involvement of liver, spleen, or lymph nodes within 1 month of diagnosis [3]. However, primary prostatic lymphoma develops extra-prostatic involvement over course of disease $[3,6]$. Bostwick et al's retrospective case study found $73 \%$ of patients with primary prostatic lymphoma developed extra-prostatic disease between 1 and 59 months after diagnosis [3]. These tumors have similar presenting complaints and clinical findings to BPH and primary prostatic adenocarcinoma, including urgency, frequency, occasional hematuria, and acute retention $[3,6,11,15-20]$. This makes consideration and evaluation of these neoplasms challenging given the relative prevalence of the aforementioned clinical entities in elderly patient.

In our case, patient presented with obstructive uropathy symptoms and was initially treated with tamsulosin and finasteride for BPH with a poor therapeutic response culminating in further evaluation with imaging, and ultimately tissue biopsy. CT scan revealed prostatic mass with right inguinal lymphadenopathy. Based on the prostate biopsy results and no evidence of distant metastases found, with no bone marrow involvement, we made diagnosis of primary NHL of the prostate (stage IIE).

There are no clear guidelines to the management of this rare tumor. The treatment modalities for primary NHL of the prostate include surgery, chemotherapy and/or radiotherapy [3, 
$6,11,12,15,16,18-24]$. The 5 -year survival was only $33 \%$ in the retrospective review of 62 patients by Bostwick et al with no significant differences between patients with primary or secondary prostatic lymphoma [3]. However, more recent case studies have reported good outcomes with rituximab or doxorubicin based chemotherapy regiment $[4,7,10,12,13$, $15,17,19-21,23-32]$. In case review of primary lymphoma of prostate in 23 Japanese patients, Nihon et al reported 11 out of 16 cases that received chemotherapy alone or associated with other treatments had a full response, whereas three of five cases treated with radiotherapy or radical prostatectomy had evidence of disease progression and died [26]. Our patient was treated with R-CHOP chemotherapy regimen. Patient achieved remission after completion of six cycles of chemotherapy. Thus, this further supports R-CHOP treatment for DLBCL of prostate.

\section{Conclusion}

In conclusion, the clinical misdiagnosis of this rare tumor is common, particularly in the elderly patients because of similar presentation to BPH or prostatic cancer. Thus, the lymphoma of the prostate must be included in differential diagnosis of the patient presenting with obstruction of the lower urinary tract especially in patients with enlargement of the gland with normal PSA level and previous history of lymphoma in other sites. Lack of response to initial medical treatment should prompt early prostate gland biopsy. Complete remission can be achievable if we diagnose and treat early before progression of disease to other organs and lymph nodes.

\section{Acknowledgments}

The Authors would like to thank to Dr. Jonathan A. Harris, MD, Department of Pathology, Maimonides Medical Center, Department of Radiology, Maimonides Medical Center, Division of Hematology and Oncology, Maimonides Medical Center, and Department of Internal Medicine, Maimonides Medical Center.

\section{Disclosures}

We confirm that this work is original. The case report was presented as a poster at American College of Physicians Internal Medicine Meeting on May 6, 2016 in Washington, DC. It has not been published elsewhere nor accepted for publication elsewhere excepted above mentioned poster presentation. All authors have read the manuscript and have approved this submission. Maimonides Medical Center IRB/Research Committee has provided permission to publish this case report.

\section{Consent}

Written informed consent was obtained from the patient for publication of this case report and any accompanying image.

\section{Conflicts of Interests}

Authors disclose no potential conflicts of interest.

\section{Funding}

There was no funding provided for this study or the preparation of this article. All the authors have read the manuscript and have approved this submission. The IRB has provided permission to publish this case report.

\section{Author Contributions}

PS, TGLT, JG, SM, ABC, and WS designed the case report, acquired and interpreted the data and wrote first draft of this case report. All authors contributed to intellectual context and approved the final manuscript.

\section{Abbreviations}

NHL: non-Hodgkin's lymphomas; PSA: prostatic-specific antigen; CT: computerized tomography; LDH: lactate dehydrogenase; PET: positron emission tomography; R-CHOP: rituximab, cyclophosphamide, doxorubicin, vincristine and prednisone; MALT: mucosa-associated lymphoid tissue; DLBCL: diffuse large B-cell lymphoma; BPH: benign prostate hyperplasia

\section{Reference}

1. Freeman C, Berg JW, Cutler SJ. Occurrence and prognosis of extranodal lymphomas. Cancer. 1972;29(1):252260.

2. Chu PG, Huang Q, Weiss LM. Incidental and concurrent malignant lymphomas discovered at the time of prostatectomy and prostate biopsy: a study of 29 cases. Am J Surg Pathol. 2005;29(5):693-699.

3. Bostwick DG, Iczkowski KA, Amin MB, Discigil G, Osborne B. Malignant lymphoma involving the prostate: report of 62 cases. Cancer. 1998;83(4):732-738

4. Sarris A, Dimopoulos M, Pugh W, Cabanillas F. Primary lymphoma of the prostate: good outcome with doxorubicin-based combination chemotherapy. J Urol. 1995;153(6):1852-1854.

5. Terris MK, Hausdorff J, Freiha FS. Hematolymphoid malignancies diagnosed at the time of radical prostatectomy. J Urol. 1997;158(4):1457-1459.

6. Bostwick DG, Mann RB. Malignant lymphomas involving the prostate. A study of 13 cases. Cancer. 1985;56(12):2932-2938.

7. Cancer facts \& Figures 2016; American Cancer Soci- 
ety. https://www.cancer.org/content/dam/cancer-org/ research/cancer-facts-andstatistics/annual-cancer-factsand-figures/2016/cancer-facts-and-figures-2016.pdf. Accessed April 14, 2016.

8. Cancer Stat Facts: Prostate Cancer. National; National Cancer Institute; Survillance,Epidemiology, and End Result Program. https://seer.cancer.gov/statfacts/html/prost. html. Accessed April 16, 2016.

9. Guidelines on Prostate Cancer; European Association of Urology. https://uroweb.org/wpcontent/ uploads/1607Prostate-Cancer_LRV3.pdf. Accessed April 26, 2016.

10. Steuter J, Weisenburger DD, Bociek RG, Bierman P, Vose J, Bast M, Loberiza F, et al. Non-Hodgkin lymphoma of the prostate. Am J Hematol. 2011;86(11):952-954.

11. Gorgel SN, Sefik E, Olgunelma V, Sahin E, Balci U, Calli AO. Primary non-Hodgkin follicular lymphoma of the prostate: A case report. Turk J Urol. 2014;40(1):57-58.

12. Alongi F, Aniko MD, Ferreri AJ, Rosso A, Cozzarini C, Fallanca F, Berardi G, et al. Consolidation radiotherapy for a rare case of extranodal mucosa-associated lymphoid tissue non-Hodgkin's lymphoma synchronous with prostate adenocarcinoma. Tumori. 2010;96(3):498-502.

13. Xu M, Yang Q, Li M, Geng W, Huang W, Chen Y. Prostate involvement by intravascular large B-cell lymphoma: a case report with literature review. Int J Surg Pathol. 2011;19(4):544-547.

14. Johnson TR, Barber DB, Teichman JM, Able AC. T-cell lymphocytic lymphoma involving the prostate presenting as elevated PSA in paraplegia: case report. J Spinal Cord Med. 1996;19(4):258-260.

15. Taleb A, Ismaili N, Belbaraka R, Bensouda A, Elghissassi I, Elmesbahi O, Droz JP, et al. Primary lymphoma of the prostate treated with rituximab-based chemotherapy: a case report and review of the literature. Cases J. 2009;2:8875.

16. Ambulkar I, Kulkarn B, Borges A, Advani S. Primary Prostatic Non-Hodgkin's Lymphoma: A case report. Indian Journal of Medical \& Paediatric Oncology. 2004;25(4):32-35.

17. Antunes AA, Dall'Oglio M, Srougi M. Primary lymphoma of the prostate: a rare cause of urinary obstruction. Int Braz J Urol. 2004;30(5):410-412.

18. Sun Li, Huang E, Chang N, Chun L, Yi Lu C, Liang J, Lee M. Malignant lymphoma involving the prostate: a case report. Therapeut Radiol Oncol. 2011;18(1):69-75.

19. Chargari C, Gillion N, Ghalibafian M, Ribrag V, Girinsky T, Magne N. [A rare case of primitive prostatic large Bcell lymphoma and review of literature]. Cancer Radiother. 2009;13(1):69-71.

20. Kakkar A, Rajeshwari M, Bhethanabhotla S, Kaur K, Jain D, Gogia A, Ray R, et al. Primary diffuse large B- cell lymphoma of the prostate: A report of two cases with diagnostic considerations. J Cancer Res Ther. 2015;11(4):977-979.

21. Rizvi FA, Seshagiri T, Antil S, Koneru SR. Primary NonHodgkins Lymphoma of the prostate presenting as haematuria. J Surg Case Rep. 2011;2011(1):1.

22. Wang C, Jiang P, Li J. Primary lymphomas of the prostate: two case reports and a review of the literature. Contemp Oncol (Pozn). 2012;16(5):456-459.

23. Zinzani PL, Martelli M, Poletti V, Vitolo U, Gobbi PG, Chisesi T, Barosi G, et al. Practice guidelines for the management of extranodal non-Hodgkin's lymphomas of adult non-immunodeficient patients. Part I: primary lung and mediastinal lymphomas. A project of the Italian Society of Hematology, the Italian Society of Experimental Hematology and the Italian Group for Bone Marrow Transplantation. Haematologica. 2008;93(9):1364-1371.

24. Tilly H, Vitolo U, Walewski J, da Silva MG, Shpilberg $\mathrm{O}$, Andre M, Pfreundschuh M, et al. Diffuse large B-cell lymphoma (DLBCL): ESMO Clinical Practice Guidelines for diagnosis, treatment and follow-up. Ann Oncol. 2012;23(Suppl 7):vii78-82.

25. Petrakis G, Koletsa T, Karavasilis V, Rallis G, Bobos M, Karkavelas G, Kostopoulos I. Primary prostatic lymphoma with components of both diffuse large B-cell lymphoma (DLBCL) and MALT lymphoma. Hippokratia. 2012;16(1):86-89.

26. Fukutani K, Koyama Y, Fujimori M, Ishida T. [Primary malignant lymphoma of the prostate: report of a case achieving complete response to combination chemotherapy and review of 22 Japanese cases]. Nihon Hinyokika Gakkai Zasshi. 2003;94(6):621-625.

27. Warrick JI, Owens SR, Tomlins SA. Diffuse large Bcell lymphoma of the prostate. Arch Pathol Lab Med. 2014;138(10):1286-1289.

28. Mounedji-Boudiaf L, Culine S, Devoldere G, Terrier-Lacombe MJ, Kattan J, Cazier A, Farhat F, et al. [Primary, highly malignant B-cell lymphoma of the prostate. Apropos of a case and review of the literature]. Bull Cancer. 1994;81(4):334-337.

29. Leung TW, Tung SY, Sze WK, Tsui WC, Wong MK, O SK. Primary non-Hodgkin's lymphoma of the prostate. Clin Oncol (R Coll Radiol). 1997;9(4):264-266.

30. Shen XJ, Zheng XG, Zhou XJ, Zhou HB. [Non-Hodgkin's lymphoma of the prostate: a report of 2 cases and review of the literature]. Zhonghua Nan Ke Xue. 2007;13(10):895-898.

31. Mermershtain W, Benharroch D, Lavrenkov K, Geffen DB, German I, Cohen Y. Primary malignant lymphoma of the prostate - a report of three cases. Leuk Lymphoma. 2001;42(4):809-811. 